\title{
Personen und Ihre Tätigkeiten für die SGO-Stiftung
}

\section{Stiftungsrat}

Dr. Markus Sulzberger

Peter Kofmel

Prof. Dr. Robert J. Zaugg

Cornelia Knecht

Hans Knöpfel

Pietro Simmen

Dr. Thomas Schmuckli

Prof. Dr. Antoinette Weibel

Stephan Loretan

Prof. Dr. Thomas Straub
Präsident

Mitglied des Stiftungsrates

Mitglied des Stiftungsrates

Mitglied des Stiftungsrates

Mitglied des Stiftungsrates

Mitglied des Stiftungsrates

Vize-Präsident

Mitglied des Stiftungsrates

Mitglied des Stiftungsrates

Mitglied des Stiftungsrates seit 2000

seit 2000

seit 2005

seit 2007

seit 2008

seit 2008

seit 2014

seit 2014

seit 2015

seit 2017

\section{Ehemalige Stiftungsräte und Stiftungsrätinnen}

Katharina Bangerter

2000-2006

Dr. Peter Schai

2000-2006

Prof. Dr. Prof. h. c. Dr. h. c. mult. Norbert Thom

2000-2012

Udo Hamm

2007-2008

\section{Geschäftsführung}

Prof. Dr. Robert J. Zaugg

2000-2004

Cornelia Knecht

2005-2006

Annette Stahel

2007-2010

Dr. Markus Sulzberger

seit 2011 